DOI:https://doi.org/10.4796o/2303-7431.25.2021.7

UDK: $81^{\prime} 38: 821.163 \cdot 42.09-31$ :

Izvorni znanstveni članak

Primljen 22. IV. 2021.

Prihvaćen 7. X. 2021.

IVONA BAKOVIĆ

Sveučilište u Mostaru, Filozofski fakultet

ivona.bakovic@ff.sum.ba

\title{
STILIZACIJA USMENOGA GOVORA U PROZI U TRAPERICAMA
}

\section{Sažetak}

$\mathrm{U}$ ovome radu analizirat će se postupci stilizacije $\mathrm{u}$ romanima proze $\mathrm{u}$ trapericama Kratki izlet Antuna Šoljana (1965.), Kužiš, stari moj Zvonimira Majdaka (1970.) i Bolja polovica hrabrosti Ivana Slamniga (1972.). U navedenim romanima pripovjedač nastupa u prvome licu pa se pripovijedanje približava usmenomu spontanom govoru, a to se postiže stilizacijom, odnosno tako što se stilističkim sredstvima nastoji stvoriti iluzija usmenoga pripovijedanja. Dijalozi u takvim književnoumjetničkim tekstovima uzimaju se kao svakodnevni dijalozi koji obiluju prekinutim rečenicama, upadicama i skretanjima s teme. Stilizacija je ostvarena pomoću nekoliko postupaka: sintaktičkom parcelacijom, uvođenjem imaginarnoga slušatelja, implikativnim izrazima i poštapalicama.

Ključne riječi: proza u trapericama; pripovijedanje; stilizacija; usmeni govor; fatička funkcija

\section{Uvod}

Jezik književnoumjetničkoga djela složeno je područje stvaranja u kojem individualni jezični izbor ne podliježe istim pravilima normativnosti 
kao u drugim funkcionalnim stilovima. U svim je funkcionalnim stilovima dopušteno birati među jezičnim inačicama, međutim, književnoumjetnički stil, za razliku od ostalih funkcionalnih stilova, ne bira između postojećih, stvarnih, nego između mogućih inačica; književnik ne radi onako kako se mora, nego onako kako se može raditi. Pojam izbora izravno je povezan s ekspresivnošću i temelji se na pretpostavci da onaj koji piše uvijek ima mogućnost izabrati jednu od nekoliko inačica koje na različite načine iskazuju istu stvar. Taj je izbor između dviju ili više inačica određen ekspresivnom vrijednošću svake od njih, a odabrat će se ona čiji emotivni prizvuk najviše odgovara cilju izraza.

$\mathrm{U}$ ovome radu analizirat će se stilizacija usmenoga govora u prozi u trapericama na primjerima romana Kratki izlet Antuna Šoljana (1965.), Kužiš, stari moj Zvonimira Majdaka (1970.) i Bolja polovica hrabrosti Ivana Slamniga (1972.). Šoljanov roman, u kojem nalazimo zametke ovoga proznog modela, pisan je kolokvijalnom sintaksom u maniri američke tvrdokuhane proze. Majdak, za kojega Krešimir Nemec kaže da je „nemilice eksploatirao model proze u trapericama ${ }^{{ }_{11}}$, motive za svoja djela nalazio je na gradskome asfaltu, u kafićima, dokolici i urbanome govoru mladih. U Slamnigovu romau Bolja polovica hrabrosti,s obzirom na njegovu kompoziciju „romana u romanu“, suprotstavljaju se dva jezika: stilizirani urbani govor mladoga inteligentnog pripovjedača i jezik starije gospođe, tete Matilde.

\section{Pripovijedanje u prozi u trapericama}

Pripovijedanje u prozi u trapericama približava se pripovjedačevu usmenom spontanom govoru, a to se načelo ostvaruje stilizacijom, odnosno tako što se stilističkim sredstvima nastoji stvoriti iluzija usmenoga pripovijedanja. ${ }^{2}$ Stilizacija je, dakle, oponašanje jezičnih sredstava tipičnih za neki oblik jezične realizacije kako bi se ostvarila određena umjetnička funkcija. U književnosti se javlja kao oponašanje nekoga

Krešimir Nemec, Povijest hrvatskoga romana od 1945. do 20oo., Školska knjiga, Zagreb, 2003., str. 156.

2 Usp. Aleksandar Flaker, Proza u trapericama, Sveučilišna naklada Liber, Zagreb, 1983., str. 98 . 
žanra ili stila nekoga djela ili nekoga pisca. Može se prepoznati i „kao specifična govorna karakterizacija, uz niz tipičnih jezičnih sredstava" ${ }^{\text {, a }}$ a može se ostvariti u i cijelome tekstu ili samo u nekim njegovim dijelovima. Jedan je od načina stilizacije $s k a z$, odnosno uvođenje pripovjedača u tekst, pri čemu se čuvaju sve karakteristične osobine koje taj lik smještaju u određenu sredinu, doba, društvenu skupinu i sl.

Stilizacija kao postupak ne spominje se u samome djelu jer je namjera da čitatelj doživi pripovijedanje kao neusiljeno i spontano.

\begin{abstract}
Stilizacija spontanog usmenog pripovijedanja kao da nas vraća idealu vjerodostojnosti onoga o čemu se pripovijeda, ali na jednoj drugoj razini nego što je to bio slučaj u prozi koju je razvila prethodna stilska formacija. Naime, usmeno pripovijedanje kao polazište takvih stilizacija suprotstavlja se modelima proze sa sveznajućim pripovjedačem i time što ukida hijerarhiju moralnih etičkih i socijalnih vrijednosti koja je karakteristična za veliki realistički roman 19. stoljeća, još više dakako za roman sa socijalno-pedagoškom društvenom funkcijom kakav je dominirao sovjetskom književnošću od tridesetih do pedesetih godina, a postao je normativnim modelom i u drugim srednjo- i istočnoevropskim književnostima četrdesetih i bar prve polovice pedesetih godina. Stilizacija usmenoga pripovijedanja pojavljivala se redovno, nasuprot prethodnim modelima, kao „obećanje nekoga upravo novoga, a ne šablonskoga, osobnog usvojenja sadržaja“... ${ }^{4}$
\end{abstract}

Pripovjedači u prozi u trapericama mogu biti različite dobi i različite naobrazbe, ali ipak imaju neke zajedničke značajke. Svi se kreću među obrazovanim ljudima, „ali ni do svojega obrazovanja, ni do kulturnih tekstova prošlosti, ni do tuđega obrazovanja (...) ne drže mnogo" ${ }^{\text {"5 }}$. O njima se ne zna mnogo: ne govore o sebi, nemaju biografiju, genealogiju, prošlost i uzore. Odbacuju društvene ustaljene strukture i biraju ili konflikt ili evaziju. S obzirom na zadanu opoziciju mi $<->$ oni na kulturnoj i jezičnoj razini, mladi pripovjedač „mora prvenstveno biti inteligentan pripovjedač koji poznaje kulturne tekstove. Odatle pojava nesvršenih učenika, nazovi-slikara i nazovi-studenata, diplomaca koji se nalaze

Marina KatniĆ-BaKaršić, Stilistika, Ljiljan, Sarajevo, 2001., str. 109.

$4 \quad$ A. Flaker, $n$. $d j$., str. 98-99.

5 A. Flaker, $n$. $d j$., str. 59. 
pred izborom, odbjeglih s naukovanja čitalaca Salingera i Defoea, likova iz gradske boheme, učenica koje bježe od kuće, vrlo različitih likova kojima je zajedničko da čitaju knjige, gledaju slike, slušaju glazbu - ali na svoj način“6.

Takvo se pripovijedanje može ostvariti na različite načine, od pripovjedača u prvome licu preko pripovjedača koji je blizak likovima jer pripada njihovu svijetu (prijatelj je ili kolega) do pripovjedača koji ne pripada njihovu svijetu, ali im je stilistički blizak. Proza u trapericama jedino ne poznaje „sveznajućeg i stilistički od govora mladih udaljenoga pripovjedača" ${ }^{\text {" }}$. Stil pripovijedanja mladoga inteligentnog pripovjedača mora se oslanjati na govoreni gradski jezik, na studentski i učenički žargon. Pritom su u prvome planu stilističke vrijednosti njegova pripovijedanja, a ne intelektualne. Svjestan je svoga položaja u društvu i načitan, ali se opire bilo kakvoj ideologiji. Sklon je rezoniranju, i to čini običnim rječnikom, pri čemu njegovi svjetonazori izgledaju naivni, ponekad i infantilni. Njegova je sintaksa jednostavna, a leksik usmjeren na isticanje predmetnoga svijeta urbane civilizacije.

\section{Stilizacija usmenoga govora}

Stilizacija usmenoga pripovijedanja u trima romanima ostvarena je s nekoliko postupaka. Jedan od karakterističnih postupaka kojim se želi stvoriti dojam autentičnosti je sintaktička parcelacija odnosno „raščlanjivanje rečenica na manje sintagmatske cjeline kojima se oponašaju pauze u usmenom govoru" ${ }^{\text {" }}$ te se stvara dojam spontanoga pripovijedanja:

Radilo se o nekom pokretu autom. Sve više mi se činio kao oružje koje treba naciljati $i$ onda ga pustiti da odjuri svom snagom kao torpedo. A komande su na izbor. Mirno samo. (treba uništiti neku živu silu?) Auto treba naciljati prema uzbrdici. Osluškivati motor, otpustiti kočnicu i dati gas, baš kao kad se uči „brdska vožnja“. (BPH: 5)

Isto, str. 60.

Isto.

Isto, str. 102. 
Druga je značajka uvođenje imaginarnoga slušatelja u tekst, odnosno izravno obraćanje slušatelju vokativom koje nalazimo u Šoljanovu Kratkom izletu:

Ovaj čovjek i ovaj svijet ovdje, za tebe je, čitaoče. (KI: 10)

Probrao sam ga na sreću iz beskrajnog niza neutralnih imena koja bi mogla pristajati tom mjestu, a koja opet svojom pripadnošću nekom drugom mjestu neće zavesti tebe, čitatelju, pruživši ti umjesto mirisa i boje moga mjesta, miris i boju svoga pravog izvora. (KI: 113)

Ljudi, te žene su bile monstruozno goleme! (KI: 45)

Prilazim im da bih osjetio njihovu blizinu. Noge su mi teške kao od olova. Sada tek jasno vidim: na zidu nema ništa. Ljudi, kažem vam, ništa. (KI: 95)

Kod Salingerova pripovjedača u obraćanju slušatelju nalazimo česte klišejizirane izraze tipične za američki kolokvijalni jezik, poput if you really want to hear about it 'ako zaista želite slušati o tome', if you want to know the truth 'ako želite znati istinu', I mean 'mislim' i sl. Takve izraze nalazimo i kod hrvatskih pripovjedača:

Bio sam kojekuda po svijetu, ali to mi je bilo najjasnije u Parizu. Što mi je zapravo pružio Pariz? Nije se udostojao ni da me primijeti. Nije mi uzvraćao pažnju, ako shvaćaš što hoću reći... Ne, nije da sam bio ravnodušan prema Parizu. Nisam bio. Dapače. Tko bi mogao biti ravnodušan - sous le pont Mirabeau coule la Seine et nos amours, i te stvari, ili što je govorio jedan moj stric, globtroter, stari fakin. (KI: 61)

Približili su se terasi kavane na kojoj je sjedjela, $u$ debelom hladu, sve sama haj rulja, koja, ako baš hoćete znati što mislim, baš mi se fućka!', s radnim narodom nema veze, ali koja zato ima više vremena za dangubu $i$ love za spiskati nego cijeli taj radni narod da se postavi na glavu $i$ istrese džepove jednu vuru poslije isplate plaća. (KSM: 98)

Flaksov unutrašnji dijalog s početka romana Bolja polovica hrabrosti, gdje se sam sebi obraća u množini, također je razgovornoga podrijetla te Slamnig tako uvodi čitatelja u njegovo „neusiljeno“ pripovijedanje: ${ }^{9}$

Svakodnevno, svakoga trenutka kao da sam govorio samome sebi da bi se sve moglo sračunati samo kad bih se smirio, kad ne bih besprekidno

9 Isto, str. 105. 
usplahireno srljao. Okej, sada ćemo se smiriti. Mjesta za parkiranje ima, ispred prostora predvidenoga samo za taksije.

Tako. Sjedimo na miru, zar ne? Promatrao sam komandnu ploču, smiješnu ručku mjenjača, ručnu kočnicu, a dolje - pedali kuplunga, kočnice, gasa. Kako je čovjek zgodno stvoren za auto! Svi ekstremiteti imaju svoju službu. (BPH: 5)

Kao važnu značajku pripovijedanja u prozi u trapericama Flaker navodi implikativne izraze odnosno izraze „širokog ali neodređenog semantičkog opsega koji potječu iz razgovornoga jezika u kojemu sugovornik zna na što se takvi izrazi zapravo odnose i koji su sadržaji njima implicirani ${ }^{\text {“10. }}$. Takvi su izrazi preuzeti od Salingerova pripovjedača (and all, and all that kind, anything like that, this stuf...), a pojavljuju se i $\mathrm{u}$ hrvatskim inačicama sve to, $i$ te stvari i kod Majdaka taj sistem:

Tko bi mogao biti ravnodušan - sous le pont Mirabeau coule la Seine et nos amours, $i$ te stvari, ili što je govorio jedan moj stric, globtroter, stari fakin. (KI: 61)

Nekako kao da se radilo o eufoniji samoga dijalekta, pa je to trebalo konkretno dokazati, pa onda možda eskalacija melosa iz zvuka samoga govora - te stvari. (BPH: 47)

Forko je sa mnom bio trpeljiv skaut, i njega je sve to zanimalo, ali se uspijevao omotati svojim profundnim pijanstvom. Da nisam svojim očima vidio kako pije, mislio bih da mu je sve to poza, da je našao zgodnu masku u kojoj donekle ostaje sebi dosljedan, mirno raspredajući svoja premišljanja, izlažući se stimulativnim upitima i poput Sokrata zapitkujući žrtvu ne bi li žrtva rodila konačnu misao, kao da je sam previše lijen da to izgura, ili kao da je iskusio bolove poroda $i$ ne želi da mu se ponove. (BPH: 81)

... stvar bi se zakomplicirala da su još imali i djece, onda stvarno ne znam kako bih se iskopala, ali i ovako, pa ne možemo reći da se zaljubila u čovjeka kojega nije pravo ni vidjela, a da i ne spominjemo da nije s njime razgovarala, pa ipak, duševni život i te stvari. (BPH: 104)

Stari dedek je, dabome, svršavao kad bi razvezao o tim danima, fijakerima, lipicanerima, volima težim od tone, krmačama koje su prasile trideset tri pajceka... uglavnomtaj sistem. (KSM: 8)

Šapnuo sam novost Glisti, da se dogovorimo kako ćemo ako stari počne izvoditi i tapšati nas po ramenu. Kak ste kaj, dečki, taj sistem. (KSM: 27)

$10 \quad$ Isto. 
- Ljubim ruke, milostiva - ponovi još jednom Glista $i$, to je trebalo vidjeti, čisto upišavanje!, ščapi je za ručicu, sagne se i počne po njoj sliniti, ljubiti gore-dolje, prevrtati očima, i taj sistem. (KSM: 39)

Tko sam, tko mi šta može, hoćeš mi cipeliše izbiksati, uglavnom taj sistem. (KSM: 141)

Čekao je samo da mu doktor kaže da je alkohol njegov smrtni neprijatelj, i taj sistem, pa da ga pošalje u božju mater. (KSM: 156)

Selindžerovske su naravi i Slamnigovi izrazi nešto kao i Majdakov ili $\operatorname{tak}(o)$ :

I doista! Stigao je honorar za Mishimu, a i još jedan koji nikako nisam očekivao, nešto kao Radio-Skoplje ili Priština, valjda su mi preveli koju radio-dramu. (BPH: 93)

Ali gore su bili nevidljivi čuvari, nešto kao strogi bolničari, mislim da su smatrali da prije svega moram zaspati, ili su pak to činili iz zlobe, a ja sam zapravo u španjolskom bunaru, vezan za ovaj bijeli krevet kao za operaciju. (BPH: 60)

Možda je to bilo samo zbog tepiha koji je očigledno vrijedio malo bogatstvo, ali još je nešto bilo negdje, nešto kao božično drvce ili tako nešto. (BPH: 18)

Pa ja nisam ni rekao da je bio samoborac, rekao sam samo da se sjećam da je u vlaku bio mrak, i onda je u mraku... no, tipke... nekakav prazni vagon je bio, a u sredini nešto kao stol... (BPH: 9)

Kad sam ga prvi put vidio tako udešenog, mislio sam da nekuda putuje ili da je kapnula neka grdna lova pa je došao da nam kaže čao lavoratori. Ili tak. (KSM: 24-25)

Kao da mu je ovaj prišapnul da je postao generalni diša INE! Ili tak. (KSM: 96)

A ovo nije bio običan cilj, biciklističke utrke ili tak, nego nešto posebno. (KSM: 105)

Mnogi su mislili da su stranci koji izvršuju zavjet ili tako nešto. (KSM: 135)

Mislio sam da je sve to slučajno, da potajno gura kolica svome starom Tateku i tako zarađuje koju kintu. Ili tako neki bezvezni kop. (KSM: 165)

U svakodnevnome je govoru, a onda i u njegovoj stilizaciji, čest izraz mislim kojim govornik upućuje na poteškoće ili oklijevanja pri 
planiranju ostatka iskaza. S obzirom na to da su sintaktični neovisni i da se mogu ispustiti, a da se ne naruši iskaz, mogu se smatrati diskursnim oznakama. ${ }^{11}$ Takve primjere nalazimo u sva tri romana:

A vidim da nemate ništa... mislim, u čemu biste... (KI: 79)

Sami ste? Mislim, već je dugo da ste ostali sami? (KI: 85)

- Mislim, cisternu su sagradili zavjet samo da sakriju ulaz u podzemni hodnik - rekao je fratar. (KI: 86)

Je li tko odonda... mislim, znate li, je li tko prolazio, jesu li išli...? Pokušali bar... (KI: 87)

Kad smo već tu... mislim, nismo mi stručnjaci, stručnjaci su odustali... ali ipak, da usput vidimo što se dade vidjeti... (KI: 89-90)

Katkada bih, da olakšam samoću - znate koliko sam u početku bio sam? - kasnije sam se navikao, mislim - katkada bih posegnuo za nekom od tih knjiga, a ona bi se pod mojim prstima raspadala u prašinu, $i$ umjesto olakšanja imao bih samo osjećaj nepopravljivog gubitka, osjećaj da sam pokvario i ono malo što se možda moglo spasiti. (KI: 96)

- Mislim, poslije, sutra? - pitao je fratar. - Razumije se, ako želite ostati neko vrijeme ovdje... (KI: 101)

- Mislim, više nikamo ne vodi... Ništa... nikakva staza? Nekamo dalje, na drugu stranu? (KI: 102)

On je, znate, bio golubar, mislim, eto tako, uzgajao je i golubove, ne za plac, i tako, ne za prodaju. (KSM: 61)

Poštar stao, sluša, a onda ode dalje vrteći glavom. Kako da ga prekinem? mislim, još dok nije kasno, još dok mu nisu izlili onu kantu zdene vode. Naljutit će se ako samo tako upadnem jer misli da govori ko papa. Misli da će promijeniti svijet, naivac jedan. Nek se izdovolji, mislim, neka ga lupe po glavi, lakše ću onda ja s njime, bolje da ga drugi trijezne nego ja. (KSM: 161-162)

Mislim, što ćemo sad jesti? Što se držiš kao da ti je pura odnijela kruh. Hoćeš li orehnjače? (BPH: 69)

Mislim, da neutralna hrvaština izgleda kao normalni medij. Treba likove okružiti stranim jezikom, tako da se ne stvori opozicija dijalekt - književni standard, već jezik a versus jezik b. (BPH: 71)

Usp. Magdalena Nigoević, „Neka načela određivanja diskursnih oznaka“, Rasprave Instituta za hrvatski jezik $i$ jezikoslovlje, Zagreb, god. XXXVII. (2011.) br. 1., str. 133. 
Ah, mladi gospodine, vi kao da ne shvaćate da sam zaokupljena, mislim, što se tiče Ane, momentom izdaje, izdaje prema Vojku, nismo valjda toliko u mraku, mislim nas dvojica. (BPH: 105)

Za razgovorni stil karakteristične su poštapalice. Najčešće se definiraju kao jezična sredstva kojima se popunjavaju stanke u govoru kako bi govornik dobio vrijeme za oblikovanje svojih misli. ${ }^{12}$ Matešić i Badurina navode da u određenju poštapalica treba uzeti u obzir sljedeće krite${\text { rije: }{ }^{13}}_{1}$ 1. semantički kriterij: semantičko pražnjenje ili desemantizacija („riječi koje neki govore bez ikakve veze s njihovim smislom “14); 2 . sintaktički kriterij: sintaktička samostalnost (sintaktički ne pripadaju rečenici); 3. fiziološko-psihološki kriterij: spontana primjena poštapalica u govoru (dok govornik traži riječ koja mu nedostaje); 4. modalno-ekspresivni kriterij: „poštapalice često izražavanju afektivno raspoloženje ili subjektivni odnos govornika prema predmetu te prema tome imaju stanovitu stilističku vrijednost ${ }^{{ }^{\prime 15}}$; 5 . estetski kriterij: minus-vrijednost, suvišne riječi kojima se služe loši govornici. Ovim kriterijima dodaju i čestotnost, ne samo na rečeničnoj nego i na tekstnoj/diskursnoj razini, pri čemu naglašavaju da nije važno statistički odrediti čestotnost, važan je „dojam o zasićenosti govora takvim jedinicima" ${ }^{\text {"16 }}$. Uzimajući u obzir da su kvalifikacije „suvišno“ i „loše“ subjektivne, relevantnim se kriterijem smatra upravo čestotnost.

U skladu s tim izdvojeni su primjeri poštapalica iz romana Kužišs, stari moj kod kojih je ispunjen prvi kriterij - semantičko pražnjenje ili desemantizacija. Međutim, imperativni oblik glagola čuti - čuj postaje poštapalicom ponajprije zbog ponavljanja u određenome diskursu. $\mathrm{U}$

12 Usp. Josıp SILIĆ, „Razgovorni stil“, Funkcionalni stilovi hrvatskoga jezika, Disput, Zagreb, 2006., str. 117.; ANĐEla FranČiĆ - LANA HudeČEK - Milica Mihaljević, Normativnost $i$ višefunkcionalnost u hrvatskome standardnom jeziku, Hrvatska sveučilišna naklada, Zagreb, 2005., str. 241.

13 Lada Badurina - Mihaela Matešić, „Poštapalice pod povećalom: o jednoj posebnoj vrsti diskursnih oznaka“, Tuzla. Grad na zrnu soli, zbornik radova, Bosansko lingvističko društvo, Tuzla, 2007./2013., str. 16-17.

14 Eugenija Barić i dr., Hrvatska gramatika, Školska knjiga, Zagreb, 1997., str. 282.

${ }_{15}$ Rikard Simeon, Enciklopedijski rječnik lingvističkih naziva, I-II, Matica hrvatska, Zagreb, 1969., str. 114., citirano prema L. BAdURINA - M. MATEŠIĆ, $n$. dj., str. 16.

16 L. BADURINA - M. MATEŠIĆ, $n$. $d j$., str. 16. 
izdvojenim se primjerima oblik čuj najčešće javlja s vokativom stari sugerirajući tako prisnost i/ili pripadnost istoj društvenoj skupini:

Čuj, stari - započeo sam ispitivanje Gliste - kaj ti se mozak ucrval? (KSM: 16)

Slažeš se, stari moj? (KSM: 115)

- Čuj, stari - započe Glista. Vino ga je bez pardoni obaralo. Nije se mogao sabrati. Šta je ono htio reći? (KSM: 116)

- Čuj, stari, ja nisam učen. Ja nisam išao u tolike škole. Ali... Čuj, ja mislim da je to pizdarija. (KSM: 116)

Mogli smo do mile volje pripovijedati i istjerati mušice iz njegove glave samo da je htio, da mi je rekao, tak $i$ tak, stari moj, to me muči, daj mi pomogni. (KSM: 165)

U nekim primjerima poštapalice imaju fatičku funkciju, tj. njima se provjerava je li komunikacija uspješna. ${ }^{17}$ Takvu funkciju imaju poštapalice kužiš i ne koje uglavnom nalazimo u romanu Kužiš, stari moj:

Samo obavezno ponesi ono čemu se klinci smiju kad to vide na stazi u parku. Kužiš? (KSM: 31)

Glistu će porez, kužiš, odvesti možda ravno u sam rajski vrt. (KSM: 53)

Kužiš, frajer ne pozna mačku, nikad je nije vidio, i to mu nije prepreka da toj mački stane bacati lire...(KSM: 99)

Kužiš, to još nisam doživio. (KSM: 113)

Kužiš, stari, u tom je biks! (KSM: 114)

$\mathrm{Pa}$, sto godina prije rezolucije Informbiroa $i$ sto i jednu godinu prije početka prvog svjetskog rata, kužiš - zezao se Filip. (BPH: 14)

Jer za mene nema razlike izmedu onog kaj kopa jamu i onog kaj je pokriva s debelo plaćenim kamenom, ne?(KSM: 8)

${ }_{17}$ „Konverzacija jest interakcijski proces u kojem sudionici razgovora daju obostrani doprinos razvoju i toku konverzacije. Izraze nalik primjerima: kontaš, kužiš, znaš, je li (je l') i sl. razumijevamo fatički, isto kao i Badurina i Matešić (2007: 19), jer je riječ o jezičnim sredstvima kojima se izravno djeluje na održavanje komunikacijskog kanala, odnosno pažnje sugovornika.“ Usp. EMina KURTIĆ - Bernes Aljukić, „Poštapalice u razgovornom bosanskom jeziku: pozicijska obilježja i funkcija poštapalica u konstrukcijskim komunikacijskim jedinicama“, Rasprave, časopis Instituta za hrvatski jezik i jezikoslovlje, Zagreb, god. XXXIX (2013.) br. 2., str. 513. 
Kad za kojom mačkom zapalimo, onda nam se ona sviđa više nego druge, ili je baš zavladala suša, ne? Nismo svi manijaci, ne? (KSM: 13)

Odem na blagajnu i blagajnici - ako je feš - ponudim da me pusti na pet minuta u svoju kabinu da zaradim jednu dobru ulaznicu, sedamnaesti red partera, tam gdje je široki prolaz, ne? (KSM: 45)

Više pomoći od mene nije mogao očekivati, ne? (KSM: 50)

Ali tebe to ne pogađa, ne?, ti ne vjeruješ? (KSM: 114)

Nismo djeca, ne? (KSM: 139)

Ako nije izmislio tu šunku i ako zbilja ima tako lijepo uređen stan, onda zbilja mora biti zaposlen u... ti boga, gdje je ono rekao?, negdje na Gornjem gradu, da svaki dan prolazi kroz Kamenita vrata, ne?, da je tajnik, koji bog?! (KSM: 146)

Pripovijedanje blisko urbanomu govornom jeziku mladih nije u jednakoj mjeri zastupljeno kod svih autora proze u trapericama te ono „varira od nenametljiva korištenja elemenata sintakse usmenog govora sa određenim leksičkim signalima kod Slamniga i Šoljana" ${ }^{\text {"18 }}$ do elemenata tzv. turpističke poetike pripovijedanja koju nalazimo kod Majdaka.

\section{Zaključak}

Ruski lingvist Roman Jakobson među funkcijama jezika navodi fatičku funkciju čija je svrha održavanje komunikacije. ${ }^{19} \mathrm{U}$ proznome tekstu fatička funkcija ostvaruje se kroz govornu karakterizaciju likova, tj. kroz prikazivanje sredine i uobičajenih formula kojima se pokazuje pripadnost određenoj društvenoj skupini. S obzirom na to da je u prozi u trapericama riječ o stilizaciji usmenoga govora, onda se dijalozi u takvim književnoumjetničkim tekstovima uzimaju kao svakodnevni dijalozi koji obiluju prekinutim rečenicama, upadicama i skretanjima s teme. Promatrajući spontani usmeni govor, odnosno njegovu stilizaciju, inherentnim svojstvom takva diskursa mogu se smatrati poštapalice koje, zbog njihove usmjerenosti na komunikacijski kanal, također razumijevamo

$18 \quad$ A. Flaker, $n$. dj., str. 123.

19 Usp. Roman Jаковson, „Lingvistika i poetika“, Lingvistika i poetika, Nolit, Beograd, 1966. str. 289 . 
fatički. Iako implikativne izraze nalazimo u sva tri romana, oni, kao i poštapalice, najviše dolaze do izražaja u romanu Kužiš, stari moj.

\section{Literatura}

- Badurina, Lada - Matešić, Mihaela, „Poštapalice pod povećalom: o jednoj posebnoj vrsti diskursnih oznaka", Tuzla. Grad na zrnu soli, zbornik radova, Bosansko lingvističko društvo, Tuzla, 2007./2013.

- BARIć, Eugenija i dr., Hrvatska gramatika, Školska knjiga, Zagreb, 1997.

- Flaker, Aleksandar, Proza u trapericama, Sveučilišna naklada Liber, Zagreb, 1983.

- Frančić, AnĐela - Hudeček, Lana - Mihaljević, Milica, Normativnost $i$ višefunkcionalnost $u$ hrvatskome standardnom jeziku, Hrvatska sveučilišna naklada, Zagreb, 2005.

- Jakobson, Roman, „Lingvistika i poetika“, Lingvistika i poetika, Nolit, Beograd, 1966.

- Katnić-Bakaršić, Marina, Stilistika, Ljiljan, Sarajevo, 2001.

- Kurtić, Emina - Aljukić, Bernes, „Poštapalice u razgovornom bosanskom jeziku: pozicijska obilježja i funkcija poštapalica u konstrukcijskim komunikacijskim jedinicama“, Rasprave: časopis Instituta za hrvatski jezik $i$ jezikoslovlje, Zagreb, god. XXXIX. (2013.) br. 2., str. 509-526.

- Majdak, Zvonimir, Kužiš, stari moj, Znanje, Zagreb, 2001.

- Nemec, Krešimir, Povijest hrvatskoga romana od 1945. do 2000. , Školska knjiga, Zagreb, 2003.

- Nigoević, Magdalena, „Neka načela određivanja diskursnih oznaka“, Rasprave: časopis Instituta za hrvatski jezik i jezikoslovlje, Zagreb, god. XXXVII. (2011.) br. 1., str. 121-145

- Silić, Josip, Funkcionalni stilovi hrvatskoga jezika, Disput, Zagreb, 2006. 
- Slamnig, Ivan, Bolja polovica hrabrosti, Večernji list, Zagreb, 2004.

- Šoljan, Antun, Kratki izlet, Večernji list, Zagreb, 2004. 
Original scientific article

Received on April 22, 2021

Accepted on October 7, 2021

IVONA BAKOVIĆ

University of Mostar, Faculty of Humanities and Social Sciences

\section{STYLIZATION OF SPOKEN LANGUAGE IN THE JEANS PROSE}

\section{Abstract}

This paper will analyze stylization procedures in jeans prose novels Kratki izlet by Antun Šoljan (1965), Kužis, stari moj by Zvonimir Majdak (1970) and Bolja polovica hrabrosti by Ivan Slaming (1972). In these novels, the narrator appears in the first person, so the narration approaches spoken simultaneous language and that is achieved by stylization. In other words, purpose of stylistic means is to create illusion of oral narrative. Dialogues in such literary-artistic texts are considered as everyday dialogues abundant with broken-off sentences, interruptions and deflections. Stylization is realized by few procedures: syntactic parceling, introducing an imaginary listener, implicative expressions and catchphrases.

Keywords: jeans prose; narration; stylization; spoken language; fatal function 